\title{
Mapping the Contribution and Participation of Saudi Institutes in Research Associated with Radiological Sciences From 2014 to 2018
}

\author{
Zameer Hussain Baladi ${ }^{1}$ and Ali Aldhebaib ${ }^{2}$ \\ ${ }^{1}$ Librarian, College of Applied Medical Sciences, King Saud Bin Abdulaziz University for \\ Health Sciences, Ministry of National Guard Health Affairs, Riyadh, Kingdom of Saudi Arabia \\ ${ }^{2}$ Director, Radiological Sciences Program, College of Applied Medical Sciences, King Saud bin Abdulaziz University \\ for Health Sciences, Ministry of National Guard Health Affairs, Riyadh, Kingdom of Saudi Arbia
}

\section{ABSTRACT}

The purpose of this observational study is, to estimate the participation of Saudi institutes in research related to radiological sciences. PubMed/Medline database is the main source to retrieve, collect and tabulate the research written or participated by authors as solo or corroborators in publications published in journals from the period $2014-2018$ in Microsoft Excel 2010. There were 2738; 5.6 authors wrote 485 manuscripts as 97 per annum and 8.08 per month. The 304; $62.6 \%$ authors were identified as a first author following by $96 ; 31.5 \%$ and $37 ; 7.6 \%$ authors as a second and third author in 485 manuscripts affiliated with institutes operational in Saudi Arabia. There are 87; 17.9\% institutes, which contributed and published their research in 232 journals allied with PubMed Indexed database. The 15 major disciplines as core subjects related to medical and radiological sciences have been figure out in this research. This is, firmly believed that one research article was published in every fourth day the past five years reflecting the participation of radiological sciences in healthcare. Technology helps in making collaborative manners to share ideas, experimental findings, designing of the research, drawing results and taking decisions and opinions.

KEY WORDS: BIBLIOMETRIC, RADIOLOGICAL SCIENCES, SAUDI ARABIA

\section{INTRODUCTION}

Radiological science used to identify the diseases and injuries of the human body in healthcare as supportive in diagnostic and treatment. Ultrasound, Magnetic Resonance Imaging (MRI), Sonography, Positron Emission Tomography (PET), nuclear medicine, Mammography and Computed Tomography Scanning (CT-Scan) are

\section{ARTICLE INFORMATION}

Received 14th Oct 2020 Accepted after revision 25th Dec 2020 Print ISSN: 0974-6455 Online ISSN: 2321-4007 CODEN: BBRCBA

Thomson Reuters ISI Web of Science Clarivate Analytics USA and Crossref Indexed Journal

\section{Clarivate
Analytics}

NAAS Journal Score 2020 (4.31)

A Society of Science and Nature Publication,

Bhopal India 2020. All rights reserved.

Online Contents Available at: http//www.bbrc.in/

Doi: http://dx.doi.org/10.21786/bbrc/13.15/21 famous technological methods to observe human tissues. Bibliometric study is a common practice for scientific institutes, libraries in healthcare societies, and pharmaceutical research to gauge the information of specific subject or sub-specialty of subject published in a particular journal or database. A bibliometric analysis provides a wide array of information on numerical data of published literature in a specific discipline or sub-specific branches of any discipline. Peer-reviewed literature in radiology required mechanism for investigators to communicate their results are focused, varying standards, evidence-based, encompassing influence on clinical or administrative management in advance human healthcare.

Open access (OA) journals allied with a PubMed Indexed database, which allows free access of academic articles to read, search, download, share, use them for indexing,

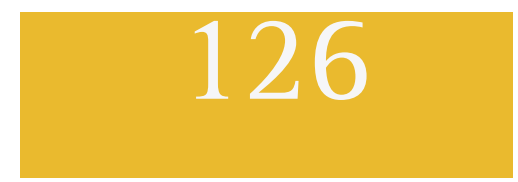


and print the full texts. Published articles are immediately available on the websites of journals and charges of publications paid by the author where only subscribers have immediate access. However, to make the article available on their personal, institutional web pages. Subsequently in April 2003 a bibliometric study was conducted to compare, the radiological research in Europe published in biomedical peer-reviewed journals indexed in web of science (WeS) with the United State of America, which were found slightly decreased.

Additionally, another study analyzed the authorship pattern in radiology publications and retrieved 142,576 articles written by 699, 257 authors participating from all over the world in National Library of Medicine MEDLINE database from 1991 to 2012 as 4.9 average authors per article. Besides this, partially similar research conducted to evaluate the contributors in the functional magnetic resonance (fMRI) literature on chemosensory. This research finds that 1660 articles, those were produced by 5200 authors, which were published in 423 journals; orbitofrontal cortex, insula, and amygdala gather good numbers of citations. In all likelihood, The Kingdome of Saudi Arabia is focused on national health care information system with the number of healthcare professionals at all levels; primary, secondary and tertiary with facilities and proficiencies of educated and trained pre-hospital caregivers, quality equipment, along with the participation of society.

These initiatives highly recognized by World Health Organization (WHO). Recently, the data of global research on the topic of rehabilitation of spinal cord injury published from 1997 to 2016 in China, downloaded from the Web of Science (WOS) and evaluated to gauge the association of country, institute, and journal. United States of America (USA), The University of Washington and The Archives of Physical Medicine and Rehabilitation found most active participators. Relatively study was conducted to discover the quantity and quality of data on the contribution of African authors in neurosurgical journals worldwide and using the PubMed database from 1999 to 2018. Thirty-one African countries contributed 974 articles in reported research.
Simultaneously, data retrieved from the Science Citation Index Expanded (SCI-E) from 1999 - 2017 on a similar study with the same objectives was conducted on research trends on global obesity. United States of America, Japan, Italy, the United Kingdom, and Turkey come-forth on five slots among the 153 countries, which were produced 50,246 articles. [10] A prospective Strategic Research Agenda on the idea of responsible research and innovation in radiological protection proposed in International Symposia on Ethics of Environmental Health with six research lines of interest and concern, i.e. 1) Effects of social, psychological and economic aspects on radiological protection behavior, 2) Holistic approaches to the governance of radiological risks, 3) Responsible research and innovation in radiological protection, 4) Stakeholder engagement and participatory processes in radiological protection research, development, policy and practice, 5) Risk communication, and 6) radiological protection cultures. PubMed resources indexed in MEDLINE, which contain approximately 30 million citations, full-text journal articles and abstracts in supporting to the literature of biomedical and life sciences under the purpose of cure and prevent diseases globally since 1996.

\section{MATERIAL AND METHODS}

The data of research on radiological sciences published from January 1st, 2014 to 31st December 2018, in the PubMed indexed journals affiliated with institutes, functioning in Kingdome of Saudi Arabia was downloaded and tabulate in MS Office Excel Sheet 2010. The commaseparated value (CSV) file, and Abstract on Note-paid used to download. Boolean operator typed "Ultrasound, Magnetic Resonance Imaging (MRI), Sonography, Positron Emission Tomography (PET), nuclear medicine, Mammography and Computed Tomography Scanning (CT-Scan)", AND appears by default, typed "Kingdome of Saudi Arabia" select as "Affiliation" in the second menu. The fourfold objective was set to identify; a) to assess the year wise growth, b) to estimate the authorship pattern, c) to evaluate the author position in the publications and d) to calculate the top ten subject specialties encompassing to radiological sciences published in journals.

\begin{tabular}{|c|c|c|c|c|c|c|}
\hline S. No & Year & $\begin{array}{c}\text { Articles } \\
\text { Download }\end{array}$ & Excluded & $\begin{array}{c}\text { Articles } \\
\text { Included } \\
\text { for analyzed }\end{array}$ & $\begin{array}{c}\text { Articles } \\
\text { per } \\
\text { year average }\end{array}$ & $\begin{array}{c}\text { Authors } \\
\text { per Article }\end{array}$ \\
\hline 1 & 2014 & 107 & 12 & 95 & 7.9 & $465(4.8)$ \\
\hline 2 & 2015 & 123 & 20 & 103 & 8.58 & $526(5.1)$ \\
\hline 3 & 2016 & 115 & 13 & 102 & 8.5 & 547 (5.3) \\
\hline 4 & 2017 & 118 & 16 & 102 & 8.5 & $656(6.4)$ \\
\hline 5 & 2018 & 111 & 28 & 83 & 6.91 & $544(6.5)$ \\
\hline Total & 574 & 89 & 485 & 8.08 & $2738(5.6)$ & 574 \\
\hline
\end{tabular}




\section{RESULTS}

This study retrieved 574 case reports, original and review articles. The inclusion criteria were only specialties and sub-specialties of medicine and allied medicine, surgery, and allied surgery to take support from the discipline of radiological sciences. Table 1 show that 2738; 5.6 authors wrote 485 manuscripts as 97 per annum and 8.08 per month average during the period $2004-2018$.

\begin{tabular}{|c|c|c|c|c|c|c|c|c|}
\hline S. No & $\begin{array}{l}\text { Authors position } \\
\text { in article }\end{array}$ & $\begin{array}{l}\text { Year } \\
2018\end{array}$ & $\begin{array}{l}\text { Year } \\
2017\end{array}$ & $\begin{array}{c}\text { Year } \\
2016\end{array}$ & $\begin{array}{l}\text { Year } \\
2015\end{array}$ & $\begin{array}{l}\text { Year } \\
2014\end{array}$ & Total & $\%$ \\
\hline 1 & Solo or Single Author & 46 & 55 & 64 & 70 & 69 & 304 & $62.6 \%$ \\
\hline 2 & Two Authors & 20 & 22 & 23 & 17 & 14 & 96 & $19.7 \%$ \\
\hline 3 & Three Authors & 9 & 10 & 6 & 8 & 4 & 37 & $7.6 \%$ \\
\hline 4 & Four Authors & 3 & 6 & 4 & 1 & 3 & 17 & $3.5 \%$ \\
\hline 5 & Five Authors & 3 & 3 & 3 & 2 & & 11 & $2.2 \%$ \\
\hline 6 & Six Authors & 1 & 1 & 2 & 5 & 3 & 12 & $2.4 \%$ \\
\hline 7 & Seven Authors & & 1 & & & 1 & 2 & $0.4 \%$ \\
\hline 8 & Eight Authors & & 1 & & & 1 & 2 & $0.4 \%$ \\
\hline 9 & Nine Authors & 1 & & & & & 1 & $0.2 \%$ \\
\hline 10 & 10 - 19 Authors & & 2 & & & & 2 & $0.4 \%$ \\
\hline 11 & 20 - 29 Authors & & 1 & & & & 1 & $0.2 \%$ \\
\hline 12 & Total Articles & 83 & 102 & 102 & 103 & 95 & 485 & \\
\hline 13 & Institutes Involve in Research & 272 & 365 & 374 & 447 & 362 & 1820 & 3.7 \\
\hline 14 & Authors Participation per article & 465 & 526 & 547 & 656 & 544 & 2738 & 5.6 \\
\hline
\end{tabular}

Table 3. The participation of the institutes in research productivity of radiological sciences existing in the Kingdome of Saudi Arabia during the period 2014 - 2018

\begin{tabular}{|c|c|c|c|c|c|c|c|c|c|}
\hline S No & Institutes & Articles & 2014 & 2015 & 2016 & 2017 & 2018 & \multicolumn{2}{|c|}{ Total with $\%$} \\
\hline 1 & King Saud University, Riyadh & 94 & 13 & 15 & 24 & 24 & 18 & 94 & $19.3 \%$ \\
\hline 2 & $\begin{array}{l}\text { King Abdulaziz University Hospital } \\
\text { \& University, Jeddah }\end{array}$ & 59 & 13 & 25 & 8 & 8 & 5 & 59 & $12.1 \%$ \\
\hline 3 & $\begin{array}{l}\text { King Faisal Specialist Hospital \&t Research } \\
\text { Center, Riyadh }\end{array}$ & 39 & 3 & 15 & 8 & 7 & 6 & 39 & $8 \%$ \\
\hline 4 & Imam Abdulrahman Bin Faisal University, Dammam & 32 & 3 & 5 & 10 & 11 & 3 & 32 & $6.6 \%$ \\
\hline 5 & King Fahad Medical City, Riyadh & 27 & 11 & 4 & 4 & 4 & 4 & 27 & $5.5 \%$ \\
\hline 6 & King Fahad Specialist Hospital at Dammam & 21 & 4 & 3 & 5 & 3 & 6 & 21 & $4.3 \%$ \\
\hline 7 & King Abdulaziz Medical City, Riyadh & 20 & 5 & & 7 & 5 & 3 & 20 & $4.1 \%$ \\
\hline 8 & Al-Qassim University & 14 & 1 & 6 & 1 & 4 & 2 & 14 & $2.8 \%$ \\
\hline 9 & $\begin{array}{l}\text { King Saud bin Abdulaziz University for Health } \\
\text { Sciences, Jeddah \& Riyadh }\end{array}$ & 13 & 3 & 2 & 1 & 5 & 2 & 13 & $2.6 \%$ \\
\hline 10 & King Abdullah Medical City, Makkah & 11 & 4 & 1 & 4 & 1 & 1 & 11 & $2.2 \%$ \\
\hline 11 & 02 Institutes Published Ten Articles & & & & & & & 20 & $4.1 \%$ \\
\hline 12 & 02 Institutes Published Nine Articles & & & & & & & 18 & $3.7 \%$ \\
\hline 13 & 02 Institutes Published Seven Articles & & & & & & & 14 & $2.8 \%$ \\
\hline 14 & 03 Institutes Published Five Articles & & & & & & & 15 & $3 \%$ \\
\hline 15 & 01 Institute Published Four Articles & & & & & & & 4 & $0.8 \%$ \\
\hline 16 & 04 Institutes Published Three Articles & & & & & & & 12 & $2.4 \%$ \\
\hline 17 & 09 Institutes Published Two Articles & & & & & & & 18 & $3.7 \%$ \\
\hline 18 & 54 Institutes Published One Articles & & & & & & & 54 & $11.1 \%$ \\
\hline
\end{tabular}


Table 2 reveals that the 304; 62.6\% authors identified as a first author following by $96 ; 31.5 \%$ and $37 ; 7.6 \%$ authors as a second and third author in 485 manuscripts. Authors had 4th to 9th position in 45; 9.2\% articles, only $3 ; 0.61$ authors relate the position from 10th to 29th in articles.
Table 3 stated that $87 ; 17.9 \%$ institutes related to the public and private sectors have been participated in the 485 publications. Total $n=330 ; 68 \%$ of articles were produced by 10 institutes. The 155; 32\% articles were harvest by 77 institutes from 2014 to 2018 in various journals.

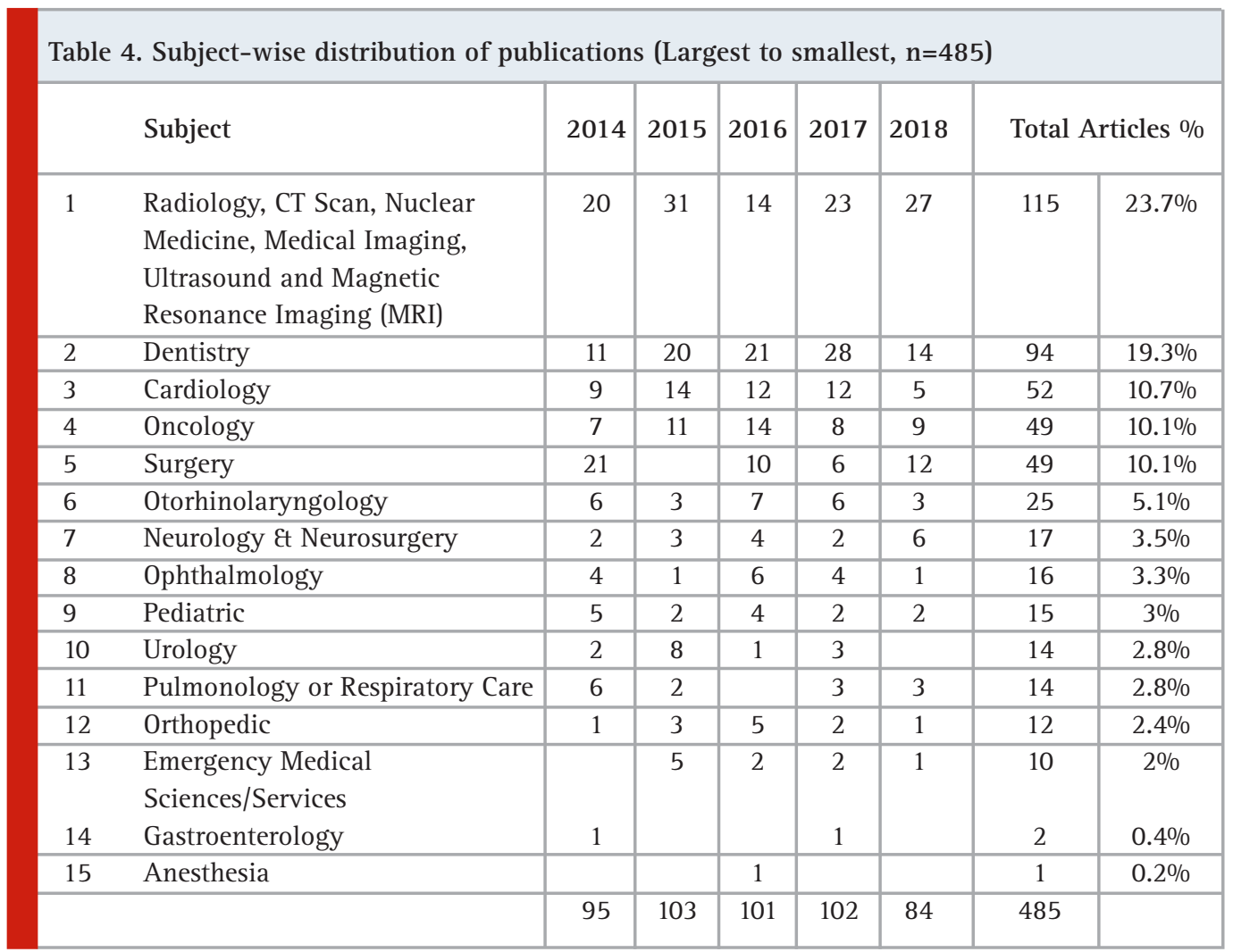

Table 5. Journal-wise distribution of publications (Largest to smallest, $n=485$ )

\begin{tabular}{|l|c|c|c|}
\hline \multirow{2}{*}{ S. no } & Name of the journal & Publications & $\%$ \\
\hline 1 & BMJ Case Reports. & 27 & $5.5 \%$ \\
\hline 2 & Saudi Medical Journal. & 19 & $3.9 \%$ \\
\hline 3 & Asian Cardiovascular Thoracic Annals. & $2.8 \%$ \\
\hline 4 & Radiation Protection Dosimetry. & 14 & $2.8 \%$ \\
\hline 5 & Oral Surgery Oral Medicine Oral & 11 & $2.2 \%$ \\
& Pathology and Oral Radiology. & 9 & $1.8 \%$ \\
\hline 7 & Neurosciences (Riyadh). & 8 & $1.6 \%$ \\
\hline 8 & Ann Saudi Med. & 7 & $1.4 \%$ \\
\hline 10 & 06 Journals published 4 article in each & 24 & $4.9 \%$ \\
\hline 11 & 5 Journals published 5 article in each & 25 & $5.1 \%$ \\
\hline 12 & 13 Journals published 4 article in each & 52 & $10.7 \%$ \\
\hline 13 & 17 Journals published 3 article in each & 51 & $10.5 \%$ \\
\hline 14 & 39 Journals published 2 article in each & 78 & $16 \%$ \\
\hline
\end{tabular}

Table 4, present 15 major specialties and sub-specialties of medicine, surgery and radiological sciences by the researcher's affiliation as core subjects in the melody of the manuscript of research. Radiological sciences with its sub-specialties published $115 ; 23.7 \%$ out of 485 articles as maximum to explain the integrated value 
of this discipline. Dentistry 94; 19.3\%, Cardiology 52; $10.7 \%$ followed.

Total 232 journals were published $\mathrm{n}=485$ articles from 2014 - 2018. Only $n=85 ; 17.5 \%$ articles published in five journals and remaining 400 articles published in 227 journals out of 232 journals.

\section{DISCUSSION \&t CONCLUSION}

Presently, a study finds 61 institutes paid contribution and participation and produced 241 articles in publishing research interrelated with emergency medical services. Majority articles $n=206$; $85.4 \%$ were written by multiauthors collaboratively out of 241 articles. The spectrum of 485 articles constructing their magnum opus. It shows that $87 ; 17.9 \%$ institutes linked to the public and private sectors of Saudi Arabia, collaborate in writings and 2738; 5.6 authors wrote manuscripts in-connection with 15 major specialties and sub-specialties of medicine, surgery and radiological sciences. King Saud University,

Riyadh take lead and presents $\mathrm{n}=94 ; 19.3 \%$ articles as single institute and followed by King Abdulaziz University Hospital \& University, Jeddah. In conclusion, it revealed that the provision of an article on every fourth day of the month shows the keen interest of researchers working in Saudi institutes specifically in radiological sciences and satisfaction with the policies, organizational vision and culture, and encouragements.

Disclaimer: This study reflects the data published in Med Indexed Journals not inclined or declined growth of any organization, city, country and standards.

Conflict of Interest: None to declare.

Funding Disclosure: None to declare

\section{REFERENCES}

Akhaddar, Ali. "African Contribution to the World Neurosurgical Literature During the Past Two Decades (1999-2018) Using PubMed Database." World neurosurgery 126 (2019): 314-321. https://doi. org/10.1016/j.wneu.2019.03.095

Al Mutairi, Mohammad Khalaf, and Dr Alabdali. "The research trends of emergency medical services in Saudi Arabia during the period 2004-2018." (2019). https:// digitalcommons.unl.edu/libphilprac/3024/

Almalki, Mohammed, Gerard FitzGerald, and Michele Clark (2011) "Health care system in Saudi Arabia: an overview." EMHJ-Eastern Mediterranean Health
Journal, 17 (10), 784-793, https://apps.who.int/iris/ handle/10665/118216

Al-Naami MY, Arafah MA, Al-Ibrahim FS (2010) "Trauma care systems in Saudi Arabia: an agenda for action". Annals of Saudi medicine. 30(1):50. https://www.annsaudimed.net/doi/full/10.4103/02564947.59374

Chow DS, Ha R, Filippi CG. "Increased rates of authorship in radiology publications: a bibliometric analysis of 142,576 articles published worldwide by radiologists between 1991 and 2012”. American Journal of Roentgenology. 2015 Jan;204(1):W52-7. https:// www.ajronline.org/doi/full/10.2214/AJR.14.12852 Eysenbach G. "Citation advantage of open access articles”. PLoS biology. 2006 May 16;4(5):e157. https:// journals.plos.org/plosbiology/article?id=10.1371/ journal.pbio.0040157

Liu, Xiaoxie, et al. "Bibliometric analysis of global research on the rehabilitation of spinal cord injury in the past two decades." Therapeutics and clinical risk management 15 (2019): 1 https://www.ncbi.nlm.nih. gov/pmc/articles/pmc6301731/

Mela G, Martinoli C, Poggi E, Derchi L. "Radiological research in Europe: a bibliometric study". European radiology. 2003 Apr 1;13(4):657-62. https://link. springer.com/article/10.1007/s00330-002-1640-7

Perko, Tanja, et al. "Towards a strategic research agenda for social sciences and humanities in radiological protection." Journal of Radiological Protection 39.3 (2019): 766. https://iopscience.iop.org/ article/10.1088/1361-6498/ab0f89/meta

Rosenkrantz AB, Pinnamaneni N, Babb JS, Doshi AM. "Most Common Publication Types in Radiology Journals:: What is the Level of Evidence?”. Academic radiology. 2016 May 1;23(5):628-33. https://doi. org/10.1016/j.acra.2016.01.002

Williamson, Peace Ossom, and Christian IJ Minter. "Exploring PubMed as a reliable resource for scholarly communications services." Journal of the Medical Library Association: JMLA 107.1 (2019): 16. https:// www.ncbi.nlm.nih.gov/pmc/articles/PMC6300231/

Yeung AW. "Bibliometric study on functional magnetic resonance imaging literature (1995-2017) concerning chemosensory perception”. Chemosensory Perception. 2018 Apr 1;11(1):42-50. https://link.springer.com/ article/10.1007/s12078-018-9243-0

Zhao, N., et al. "Global obesity research trends during 1999 to 2017." Medicine 98: e14132. https://www.ncbi. nlm.nih.gov/pmc/articles/PMC6358342/ 